\title{
The Compilation of the Cost Accounting Textbook Respecting to Six Key Points
}

\author{
Li Yanli \\ Management department \\ Xuzhou Institute of Technology, XZIT \\ Xuzhou China \\ lylay@126.com
}

\begin{abstract}
With the increasingly fierce competition among enterprises, the place of cost accounting in enterprises is becoming more and more important; it is necessary to put forward specific requirements about the compilation of textbook of the cost accounting according to the demand of times development. On account of this, this paper believes that there are six key points to respect when compile the cost accounting textbook: ensure the stability of the textbook writers; attention to the systematicness of textbook structure; highlight the interestingness of the textbook content; pursue the integral logicality of the textbook; emphasize the practicalness of the textbook application; embody the forwardness of cost accounting knowledge.
\end{abstract}

Keywords—cost accounting textbook; systematicness; interestingness; logicality; practicalness; forwardness

\section{INTRODUCTION}

With the increasingly fierce International competition, the profit margin of enterprises rapidly shrinks which makes the correct calculation of products cost and the cost control enforcement take the critical positions in administrative decisions and the information provided by cost accounting has become an important factor for the administrators to effectively carry out management and improve competition position. All of these contribute to the importance increase of the cost accounting course as one of the core courses of the economics and management majors in colleges and universities; the practicalness and development should be highlighted in its theoretical property according to the times requirements, thereby it put forward higher requirements on the compilation of cost accounting textbook.

The current cost accounting textbooks are mainly two types: one is the textbook for higher vocational colleges mainly focusing on college education and TV university education; the other type is the textbook for the undergraduate education in regular higher education institutions. Textbooks for higher vocational colleges require students mainly to acquire the cost accounting function and emphasize accounting operations related to cost accounting, so the structure systems of these textbooks are approximately same: take the cost accounting as the main content and briefly introduce the analysis of cost statements. While it is difficult to unify the teaching target orientations of the regular higher education institutions, so there is certain difference between the undergraduate education

Jiangsu Colleges and Universities Brand Majors Construction Engineer Funding Program. textbooks; but from the link among all the courses of the regular higher education institutions and the common characteristics of teaching requirements, the compilation of high quality cost accounting undergraduate education textbook should keep to the following six key points.

\section{ENSURE THE STABILITY OF THE TEXTBOOK WRITERS}

When compile the cost accounting textbook, it is necessary to set a stable and capable author team firstly and there shouldn't be too many authors taking 3 persons as the maximum quantity of authors. (1) Being stable is to require the authors to attend the whole compilation process including the determination of the outline and the general ideas in the early stage, the composing of the content of specific chapters in the later period and the proof-reading after the compilation is finished. This can ensure the integrity, systematicness and consistency of the textbook, improve the quality of the textbook and guarantee the compilation efficiency in order to avoid the interruption of the textbook compilation when some author drops out during the compilation process. (2) Being capable is to require the authors to be possessed with good academic base and abundant practical experience in the field of cost accounting teaching and scientific research and occupied with rigorous logical thinking and strong writing ability. Good academic foundation can keep the textbook content to keep pace with times and reflect the latest theoretical research achievements; abundant practical experience can well combine theory with practice and keep the practicability of the textbook; many years' teaching experience accumulation can keep the authors know about the learners' mentality and interest and compile the textbook from the perspective of learners' comprehension making the textbook popular and easy to understand.

\section{AtTENTION TO THE SYSTEMATICNESS OF TEXTBOOK STRUCTURE}

Based on a brief understanding of 30 representative cost account textbooks for undergraduate education, the current textbook structure is taking cost accounting as main part with the addition of the preparation and analysis of cost statement. In addition, some textbooks have also added the content of cost control and cost planning; some textbooks introduce some special cost accounting methods such as the standard cost method, variable cost method, activity-based costing etc; some 
textbooks explain some content about strategic cost management and cost accounting information system; some textbooks add the content of cost accounting feature and introduce some state-of-art theories of cost accounting.

There are all together seven functions of cost accounting including prediction, decision-making, control, planning, accounting, analysis and evaluation among which the accounting is the core of cost accounting, so there is no doubt that all of cost accounting textbooks take cost accounting as the main content and the introductions of other functions should be optional considering the limit of credit hours of cost accounting undergraduate courses and the repetition with other related courses. First of all, there are 50 credit hours for cost accounting course in colleges and universities generally; with this time limit, the cost accounting textbooks couldn't have too much content, if every function content have all be involved, then the basic cost accounting function cannot be highlighted and teachers can only well explain partial content or give a brief introduction to all content because of the credit hours limit. If teachers only explain partial content, then students will complain about the thick books with high prices; if teachers only give brief introductions to all content, maybe the students cannot acquire the core cost accounting content and cannot finish the basic cost accounting operations when they go to their posts. So the cost accounting textbooks cannot cover everything in detail and they should explain the cost accounting core content namely accounting briefly, comprehensively and systematically to the point and selectively introduce other content. Secondly, about the selection of other functions introductions, they should consider the relation between cost accounting, management accounting and other related courses and remove the crossed and repeated content. Four functions of cost accounting functions including prediction, decision-making, control and evaluation are all important content of management accounting; cost accounting function once was explained in the course of Economic Activity Analysis but now the universities barely have this course; since currently the enterprises pay more and more attention to make cost management by cost planning, the cost accounting textbooks should take the core function of cost accountant namely cost accounting as the principal line and introduce cost analysis and cost planning functions on the basis of the consideration of the requirements for the training of application-oriented talents and the current need of enterprises and make the students well acquire the basic cost accounting and meanwhile enable them to analyze the existing cost of the enterprises and plan the cost for the future. Thus, the integration of cost accounting courses and the management accounting courses can ensure the systematical cost accounting knowledge structure with complete functions and avoid the disadvantage of course repetition and waste of credit hours.

\section{HighLIGHT THE INTERESTINGNESS OF THE TEXTBOOK CONTENT}

The cost accounting courses mainly focus on the accounting and management of the expenses generated in the production process of enterprises and is boring and with a lot of content and many different kinds of calculation methods. In order to increase the students' interest, on the basis of representing systematic and necessary content, the cost accounting textbooks should add plentiful flexible items in different forms such as knowledge cards, summary of delicate and easy to understand, simple and clear intelligent memory, vivid and interesting cases, knowledge link to connect knowledge points of former and next parts etc in order to make the textbook content novel and interesting to read.

These flexible items will not only make the boring content rich and colorful and also have great meaning respectively. (1) Knowledge card. On account of the limit of credit hours, the cost accounting textbooks need to clearly and briefly introduce the cost accounting, the establishment and analysis of cost statement and cost planning etc; the related knowledge points that the students need to know about can be introduced by cards and this can separate the content to remember from the content to know about, make the students grasp the important content, widen the students horizon and enrich their knowledge accumulation by the application of knowledge cards. The content of the knowledge cards must be knowledge points related to cost accounting and can include the current regulations related to cost accounting of out nation's financial regulations; similarity and difference between domestic and abroad related knowledge; make a discrimination and analysis of some special concepts such as cost collection and cost distribution; some practical operations among enterprises etc. (2) Small cases. The cost accounting needs to be operated and used in enterprises practical situations and is a quite practical course, so except for the leading cases at the beginnings of each chapter, cost accounting should also set some interesting and vivid small cases close to enterprises practical situation in the corresponding theoretical knowledge points for example, when making an introduction of enterprises production features and classifications, it is possible to take actual enterprises as examples of different production types which will make the theoretic knowledge no longer boring and easy to understand and grasp. (3) Intelligent memory. The intelligent memory program requires the authors have abundant teaching experience, not only be good at regularity summarization but also be able to analyze the difficult and important points from the mentality and perspective of students; helps learners strengthen the understanding of cost accounting content and increase study interest of the learners in understanding. For example, the distribution of auxiliary production cost is difficult point of cost accounting course, so multiple intelligent memory columns can be set up focusing on content difficult to understand for students: declare that the key of auxiliary product cost distribution is the calculation of unit cost and list the general calculation formula for unit cost calculation before listing all the methods; cross allocation and external allocation can be illustrated by structure chart when introducing the reciprocal allocation approach; the algebraic distribution determines equation with two calculation methods of the total cost of some production workshop as thinking ideas. (4) Knowledge link. When arrange the content of cost accounting, textbooks usually firstly introduce the collection and distribution of expenses and then introduce the cost accounting methods; the former is the base of the calculation of the later. So when the knowledge points of former chapters will be adopted in the cost calculation method, it is possible to 
implement knowledge link which will ensure the continuity of the textbook and also make students understand the link between former and later content. (5) Brief summary. Since many methods can be adopted for expense distribution and cost calculation in the field of cost accounting, in order to make students think clearly and get a clear understanding of multiple complex and similar methods, the brief summaries will play an important role. For example, after the introduction of the distribution methods of auxiliary production expenses, summarizing the regularities of different methods in the form of brief summaries will help students understand the complex methods and memorize them in the form of framework. Please refer to Fig 1.

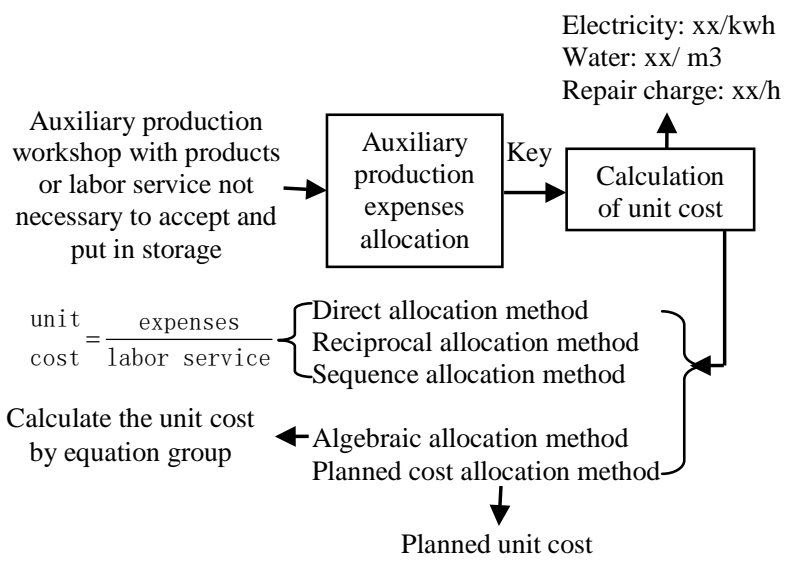

Fig. 1. Brief summary of auxiliary production expenses distribution method

\section{EMBODY THE FORWARDNESS OF COST ACCOUNTING KNOWLEDGE}

Cost accounting as a subject with extensive application keeps changing its content with the development of times; in order to make students keep pace with the times and know about the modern development situation of cost accounting, the frontier knowledge of cost accounting should be embodied in the compilation of cost accounting textbooks. Among all the current cost accounting textbooks, multiple textbooks have also added the frontier knowledge of cost accounting on the basis of covering basic costing accounting functions. The textbook Cost Accounting compiled by Yu Fusheng from Renmin University of China introduces the cost accounting frontier with an individual chapter including calculation of environment cost, quality cost and operation cost; the cost accounting textbook compiled by Wan Shouyi from Dongbei University of Finance and Economics introduces the operation cost method with an individual chapter; the Cost Accounting mainly compiled by Yue Yanfang from Shanghai University of Finance and Economics illustrates the strategic cost management, operation cost method, quality cost management and environment cost management in the fourth chapter The Strategic Cost Management which is similar to the content in the cost accounting textbook of the Renmin University of China; the cost accounting textbook compiled by Fan Xiaoqi from Zhejiang Gongshang University established a chapter of the development of cost accounting including the strategic cost management, product life cycle cost management, operation cost calculation and quality cost management. It is thus clear that the frontier knowledge which needs to be embodied in cost accounting textbooks should include the strategic cost management, operation cost method, environment cost calculation and quality cost management at least. As far as current cost accounting textbooks status, part of textbooks embody the related content of frontier knowledge but basically copy that from the western countries and haven't been localized which means they haven't established accounts and planned specific calculation with the combination of the regulations of our country's Accounting Standards for Business Enterprises or set example cases for illustration taking the practical situations of our country enterprises into account. While these works cannot be completed by individual author or author groups, they need the common research of academic scholars and even a special scientific research task led by the Ministry of Finance if necessary. The cost accounting textbooks need also include these frontier knowledge and make a statement of the current disadvantage and defects making students know about the advanced content of cost accounting and encouraging students to explore the possible problems and inapplicability of these frontier knowledge during the application in our country; students may research these problems in theory at university and in practice during working which will contribute to solve the applicability problems of the modern cost accounting frontier knowledge introduced from western countries and indeed improve the cost accounting level of our country enterprises. The authors of cost accounting textbooks should also pay close attention to the development of this frontier knowledge, update the textbook content timely and ensure the textbook to be modern and applicable.

\section{PURSUE THE INTEGRAL LOGICALITY OF THE TEXTBOOK}

Based on the above analysis, the cost accounting textbooks should include four main parts namely cost calculation, cost analysis, cost planning and the frontier knowledge of cost accounting; in order to separate the key content cost accounting function with other two functions, it is possible to distribute the whole textbook content into four parts: the first part as introduction presents the meaning and function of cost, the object and function of cost accounting etc; the second part as cost accounting function introduces the knowledge related to cost accounting in specific chapters; the third part as the other functions of cost accounting respectively introduces the cost analysis and cost planning function in two chapters; the fourth part is about the frontier knowledge of cost accounting.

When edit the chapters and sections of the second part namely cost accounting function, it is necessary to develop from easy to difficult and step by step. Put the requirements of cost accounting, the classification of expenses, cost accounting procedures and cost accounting methods summary as the precondition of accounting in one chapter to introduce and put the allocation and distribution of element expense, auxiliary production expenses and manufacturing expenses and the loss on defective products and business-interruption loss into one chapter as the basic knowledge of cost accounting; with this basic accounting knowledge, it is possible to introduce the basic methods of cost calculation and auxiliary methods next and at last complete the whole content with the establishment 
of cost statement. Thus from the precondition of accounting to accounting basic knowledge, accounting methods and then to the establishment of cost statement at last, the cost accounting function is introduced step by step forming the logical development process from theory to method and application and helping train learners scientific ways of thinking. In order to clearly state the connections among all chapters, it is possible to set the fixed column namely the knowledge structure chart at the beginning of each chapter, if there are lots of content or complex content in some section, it is ok to set knowledge structure chart (Fig 2) in the front of that section. The knowledge structure charts can clearly and briefly show the content of this chapter or section and plays a leading role making complex content brief and clear and leads students to grasp the logic relations of the learned content and take the knowledge points in a clear thinking way.

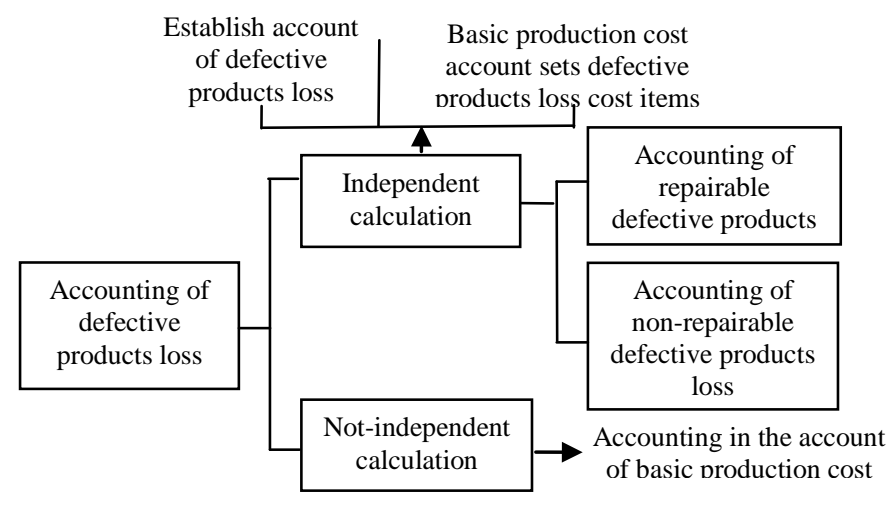

Accounting of business-interruption loss

Fig. 2. Knowledge structure chart of defective products and businessinterruption loss

\section{EMPHASIZE THE PRACTICALNESS OF THE TEXTBOOK APPLICATION}

The cost accounting comes from enterprises practice and will serve for enterprises practice so it is necessary to emphasize the close connection between the theory and practice during the compilation of the cost accounting textbook; on the basis of enough theoretical statements, the highlight of the practice orientation will need to fulfill the following aspects. (1) Example question. The setting of example questions is the basic requirement for the compilation of textbooks; in the cost accounting textbooks, example questions should be provided with explanations to each knowledge point related to practice and the explanation of example questions should be variable, closely related to the actual cost accounting business of enterprises, applicable for different situations frequently happened in enterprises and easy to understand. For example, for the introduction of the expenses distribution of each element, there should be some example questions focusing on the indirect charge allocation and also the whole expenses situation of the enterprise including the consumption of each department and the direct and indirect expenses about the products manufacturing in the workshop; another example is that the five allocation methods of the auxiliary production expenses should set the example questions based on the actual data from the corresponding enterprises and it is better to avoid that five methods share one example question. (2)Cases. Set leading case at the beginning of each chapter and the leading cases can be the actual situations of enterprises and also can be designed by the authors themselves. The function of the leading case is either to emphasize the importance of the content in this chapter or to put forward questions related to this chapter content, trigger the readers' thinking, but the fundamental objective is to attract the attention of the learners and lead them to be interested in the content. In addition, it is necessary to insert some small cases and tips; the small cases can work together with the theoretical knowledge contributing to help students develop practice and application ability; small tips can introduce content related to accountant occupational ethics and attentions for the actual application of the theoretical knowledge; taking accountant occupational ethics content into textbook can contribute to train accounting talents observing law and disciplines. (3) Practical data. The cost accounting is based on all kinds of original certificates including material requisition, returned material notes etc and registers different kinds of subsidiary accounts; when the compilation involves these original certificates and account books, it is better to use the practical data of enterprises which will help students know about the real situations of enterprises and have a sensorial understanding of enterprises practices. (4)Reflection questions. Set some reflection questions after the introduction of one chapter. There can be many types of reflection questions such as analysis questions of cases related to the knowledge points in this chapter and calculation questions. Since the cost accounting mainly focuses on the application of calculation methods compared to financial accounting, calculation questions should be set according to the difficulty and key points at the end of each chapter making students familiar with the application of calculation method and improve their practical operational ability. Many textbooks haven't set reflection questions and practices after the learning content of each chapter instead, there will be a dedicated practice book for students; currently some universities don't allow to order the matching practice books in order to reduce the burden of students, given that, the reflection questions after each chapter content are especially important.

\section{REFERENCES}

[1] Peng Hongchao. The Study on the Cost Accounting Teaching System Based on the New Cost Accounting Regulations.Finance and accounting news report,2014(9)(In Chinese).

[2] Zhou Xiaohui The Analysis of the Current Situation of Cost Accounting Textbooks and Suggestions for Improvement.Caikuai Yuekan, 2010(11)(In Chinese).

[3] Li Yanli. Discussion of inquiry-based learning and application on Cost Accounting. Financial and Accounting Communication,2014(12)(In Chinese).

[4] Li Yanli. Design the courseware of Cost Accounting based on six characteristics . Friends of Accounting,2012(9)(In Chinese).

[5] Li Yanli. Several issues needing attention on auxiliary production expenses distribution teaching . Finance and Accounting Monthly,2009(11)(In Chinese).

[6] Ren Yandong, Tian Lijuan, Xue Yujia. School-based teaching textbook of cost accounting practical training and multimedia resource construction research . Liaoning higher vocational journal,2015,17(6)(In Chinese) 